\title{
Magnetic, Electrical, Thermal and Elastic Properties of High-Mn Electrical Steel
}

\author{
Jaehoon $\mathrm{KIM}^{1)}$ Yuxin $\mathrm{SONG}^{2)}$ and Takashi FUKUDA ${ }^{2 / *}$ \\ 1) Electrical and Electron Research Group, Technical Research Lab., POSCO, 6261, Donghaean-ro, Namgu, Pohang, \\ Gyeongbuk, 37859 Korea. \\ 2) Department of Materials Science and Engineering, Graduate School of Engineering, Osaka University, 2-1, Yamada-oka, \\ Suita, Osaka, 565-0871 Japan.
}

(Received on August 12, 2019; accepted on September 18, 2019)

\begin{abstract}
We have studied influence of $\mathrm{Mn}$ doping on electrical resistivity, magnetic properties, specific heat and elastic constants of electrical steels. The electrical resistivity of the steel with $\mathrm{Mn}$ content of 1.5 mass\% (HM steel) is by $13 \%$ higher than that of the steel with Mn content of 0.3 mass $\%$ (LM steel) at $5 \mathrm{~K}$, and the difference decreases as temperature increases. In addition, magnetocrystalline anisotropy constant $K_{1}$ of the HM steel is smaller than that of the LM steel by $15 \%$ or more in a wide temperature range. Despite of these benefits as electrical steel, the spontaneous magnetization of the HM steel is by $1.9 \%$ lower and specific heat is by $0.9 \%$ higher than that of the LM steel. Elastic constants of the two steels are almost the same. Moreover, Curie temperature of the HM steel is by $14 \mathrm{~K}$ lower than that of the LM steel.
\end{abstract}

KEY WORDS: electrical steel; magnetocrystalline anisotropy constant; electrical resistivity; spontaneous magnetization; specific heat; elastic constant; Curie temperature.

\section{Introduction}

Recently, as the markets of eco-friendly vehicles such as hybrid electric vehicle (HEV) and electrical vehicle (EV) grow rapidly, the role of conventional internal combustion engines has been reducing. They will be replaced by electric traction motor to achieve high fuel efficiency and to reduce environmental issues, such as $\mathrm{CO}_{2}$ emission and air pollution. One of the most important technologies for the replacement is manufacturing of traction motors with high efficiency. Since traction motors are made of non-oriented electrical steel and the steel acts as magnetic path in motor, typical properties of non-oriented electrical steel such as low core loss are directly related to motor characteristics.

Generally, traction motors rotate at high speed; therefore, it is necessary to reduce iron loss at high frequencies. A good way to reduce iron loss at high frequencies is to increase electrical resistivity. That is why electrical steels for traction motors contain a large amount of silicon and aluminum. Actually, the total amount of $\mathrm{Si}$ and $\mathrm{Al}$ in commercial products reaches approximately 4.0 mass $\%{ }^{1-6)}$ If the total amount of these elements exceeds this value, brittleness increases sharply. ${ }^{7,8)}$ This is disadvantage for cold rolling. In order to further increase electrical resistivity while minimizing deterioration of cold workability, it is useful to add $\mathrm{Mn}$ in non-oriented electrical steel. ${ }^{9}{ }^{\text {) }}$

Previous research on the effect of $\mathrm{Mn}$ addition in non-oriented electrical steel has mainly focused on controlling

* Corresponding author: E-mail: fukuda@mat.eng.osaka-u.ac.jp DOI: https://doi.org/10.2355/isijinternational.ISIJINT-2019-512
$\mathrm{MnS}$ in the steelmaking process and the subsequent annealing process. In these studies less than 0.5 mass $\%$ Mn was usually added to form coarse MnS inclusions/precipitates, ${ }^{10-17)}$ which result in the improvement of grain growth during annealing. In order to increase electrical resistivity, a larger amount of Mn should be added because increasing effect in resistivity by Mn-doping is a half of that by Si-doping and Al-doping. However, little research has been done on the change of material properties when a large amount of $\mathrm{Mn}$ is added. In particular, research on fundamental magnetic properties such as magnetocrystalline anisotropy and saturation magnetization can provide important information to predict the traction motor performance and can result in providing insight for the development of a new electric steel with low iron loss at high frequency.

Therefore, the purpose of the present study is to investigate the effect of $\mathrm{Mn}$ addition on magnetic properties such as magnetocrystalline anisotropy constant, spontaneous magnetization and Curie temperature of non-oriented electrical steel. In addition, we examine the effect on elastic constants and specific heat. Based on the results, we will discuss the temperature dependence of the magnetic properties obtained.

\section{Experimental Procedure}

Two electric steels with different Mn content were prepared. One is conventional high-grade non-oriented electrical steel containing 0.3 mass $\% \mathrm{Mn}$, which is widely used as core material of traction motor of vehicles. The other is newly designed steel containing 1.5 mass $\% \mathrm{Mn}$; electrical resistivity of which is expected to be by $10 \%$ higher than conventional 
high-grade one. ${ }^{18)}$ We call the former alloy as low manganese (LM) steel and the latter as high manganese (HM) steel. Composition of the remaining elements such as $\mathrm{Si}$ and $\mathrm{Al}$ are essentially the same save the balance element (Fe).

Ingots of these steels were prepared by induction melting. The ingots were heat-treated at $1327 \mathrm{~K}$ for $3 \mathrm{hrs}$, and then hot rolled to $2.5 \mathrm{~mm}$ thickness. The rolled plates were annealed at the same temperature for $300 \mathrm{~s}$. The plates were then cold rolled to sheets of $0.25 \mathrm{~mm}$ thickness, and finally annealed at $1223 \mathrm{~K}$ for $60 \mathrm{~s}$.

Specimens for electrical resistivity, heat capacity and differential scanning calorimetry (DSC) measurements were cut from these sheets. Electrical resistivity was measured by a four probe method with a cooling and heating rate of 1 $\mathrm{K} / \mathrm{min}$. Specific heat was measured by a relaxation method. DSC measurements were made with a cooling and heating rate of $10 \mathrm{~K} / \mathrm{min}$.

Single crystals of the two steels were grown in an alumina crucible by a Bridgeman method with a growth rate of $8 \mathrm{~mm} / \mathrm{h}$ in a purified argon gas flow. The single crystals were annealed at $1223 \mathrm{~K}$ in evacuated quartz tubes for $24 \mathrm{~h}$ for homogenization and cut into disks with $3.5 \mathrm{~mm}$ in diameter and $0.3 \mathrm{~mm}$ in thickness. The surface of each disk was parallel to (01) $)$ plane. Similar disk of pure iron was purchased from Crystal Base Co., Ltd. Magnetization curves were measured in three principal crystallographic orientations, [100], [011] and [111], which lie in the disk. Magnetization measurements were made by a vibrating sample magnetometer (VSM).

Elastic constants were measured by an ultrasonic pulsed echo phase comparison method with a propagation direction of [01 $\overline{1}$. The sound velocities of the longitudinal wave and two transverse waves with vibrating direction of [100] and [011] were measured by the transmission mode.

\section{Results}

Figure 1 shows electrical resistivity of the LM steel and the HM steel measured in the cooling process and the sub- sequent heating process. There is no hysteresis between the cooling and heating processes for both steels. The electrical resistivity of the HM steel is higher than that of the LM steel by $13 \%$ at $5 \mathrm{~K}$. The difference reduces as temperature increases. The value of resistivity at $300 \mathrm{~K}$ is in agreement with the empirical formula proposed before. ${ }^{18)}$ Incidentally, we notice abnormal behavior in resistivity of the HM steel below $50 \mathrm{~K}$. That is, electrical resistivity increases with decreasing temperature below $50 \mathrm{~K}$. We will discuss on this behavior later.

Figure 2 shows magnetization curves at $4.2 \mathrm{~K}$ of the HM steel and the LM steel obtained in the field removing process from $0.5 \mathrm{~T}$. Magnetization curves of pure iron obtained at the same temperature are shown in Fig. 2(c) for comparison. Magnetic field was applied in the three primary directions [100], [011] and [111]. For all specimens, [100] is most easy to magnetize and [111] is most hard to magnetize. We evaluated magnetocrystalline anisotropy constant $K_{1}$ as

$$
K_{1}=4\left(\mathrm{E}_{[011]}-\mathrm{E}_{[100]}\right),
$$

where $E_{[011]}$ is magnetic energy necessary to magnetize in the [011] direction and $\mathrm{E}_{[100]}$ is that in the [100] direction. The value $K_{1}$ at $4.2 \mathrm{~K}$ is $39.1 \mathrm{~kJ} / \mathrm{m}^{3}$ for the LM steel and $33.1 \mathrm{~kJ} / \mathrm{m}^{3}$ for the HM steel and $51.7 \mathrm{~kJ} / \mathrm{m}^{3}$ for pure iron. Here we used the density of $\rho=7.55 \times 10^{3} \mathrm{~kg} / \mathrm{m}^{3}$ for the LM and HM steels, which was directly determined from the mass and volume of the ingots and $\rho=7.85 \times 10^{3} \mathrm{~kg} /$ $\mathrm{m}^{3}$ for pure iron. The value of pure iron is consistent with a reported value of $52.0 \mathrm{~kJ} / \mathrm{m}^{3}$ at $20 \mathrm{~K} .{ }^{19)}$ Similar measurements were made at different temperatures and the value of $K_{1}$ is plotted as a function of temperature in Fig. 3(a). At any temperature examined, $K_{1}$ of pure iron is the largest and $K_{1}$ of the HM steel is the smallest.

Concerning another magnetocrystalline anisotropy constant $K_{2}$, the value is evaluated as follows.

$$
K_{2}=27\left(\mathrm{E}_{[111]}-\mathrm{E}_{[011]}\right)-9 K_{1} / 4
$$

The value $K_{2}$ obtained at $4.2 \mathrm{~K}$ is $-25.5 \mathrm{~kJ} / \mathrm{m}^{3}$ for the $\mathrm{LM}$ steel, $10.7 \mathrm{~kJ} / \mathrm{m}^{3}$ for the HM steel and $-3.0 \mathrm{~kJ} / \mathrm{m}^{3}$ for pure
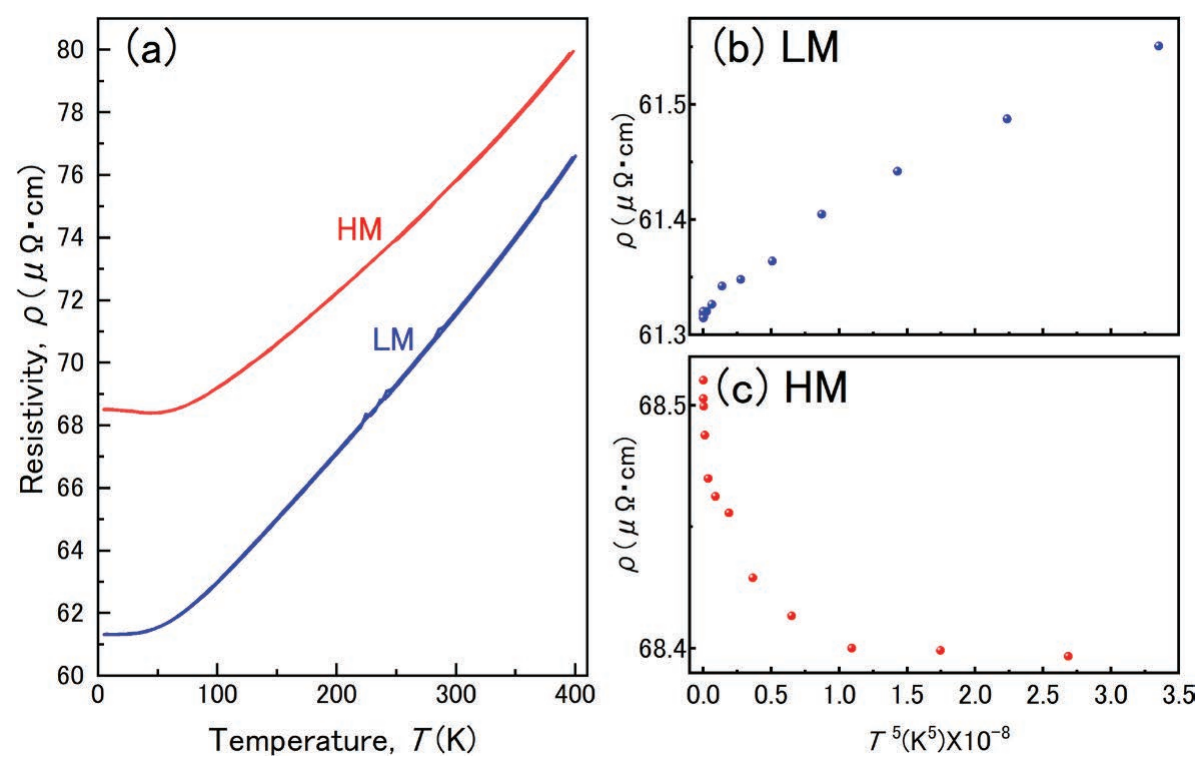

Fig. 1. Temperature dependence of electrical resistivity of the LM and HM steels (a), and their magnification below 50 $\mathrm{K}$ (b), (c). (Online version in color.) 


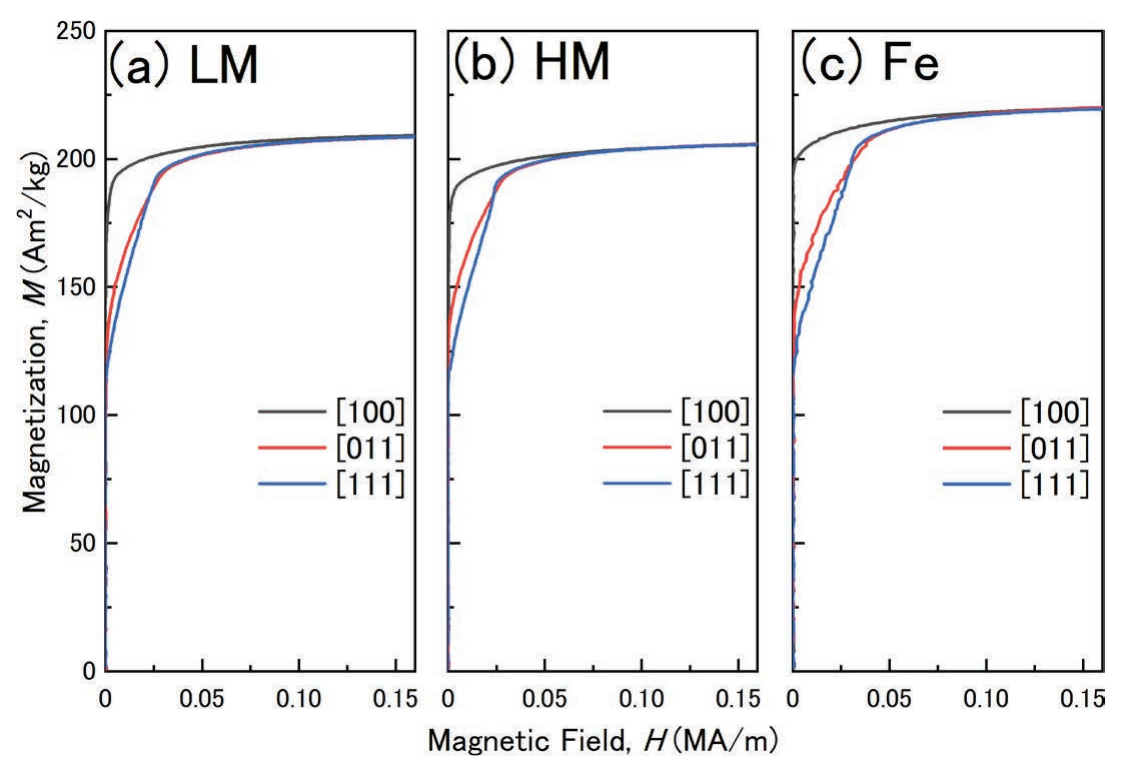

Fig. 2. Magnetization vs. magnetic field curves of the LM steel (a), the HM steel (b) and pure iron (c) obtained at $4.2 \mathrm{~K}$ each crystallographic orientation. (Online version in color.)
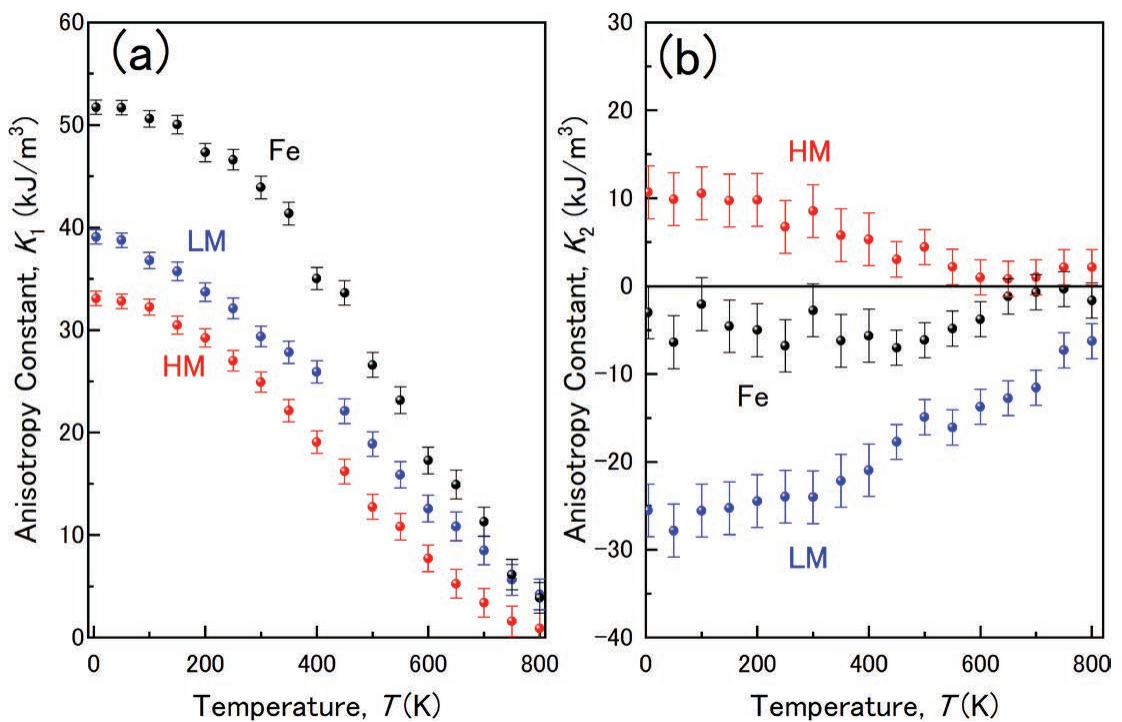

Fig. 3. Temperature dependence of $K_{1}$ (a) and $K_{2}$ (b) of the LM steel, the HM steel and pure iron. (Online version in color.)

iron. The value $K_{2}$ of pure iron is slightly smaller than previously reported value of $-1.6 \mathrm{~kJ} / \mathrm{m}^{3}$ at $20 \mathrm{~K} .{ }^{19)}$ The value $K_{2}$ obtained at various temperatures is shown in Fig. 3(b). At any temperature examined, the value $K_{2}$ is the largest in the HM steel and the smallest in the LM steel. This is due to the fact that the energy difference $\left(\mathrm{E}_{[111]}-\mathrm{E}_{[011]}\right)$ is the largest in the HM steel and the smallest in the LM steel, as shown in Fig. 2(b).

Figures 4(a) and 4(c) show typical examples of Arrot plots $^{20)}$ ( $M^{2}$ vs. $H / M$ curves) obtained from magnetization curves $(M-H$ curves) in the [001] direction of the LM and HM steels. Every curve shows a linear relation in a high field region. By extrapolating the linear relation to zero field, we obtained spontaneous magnetization $M \mathrm{~s}$. The value of $M$ s obtained in this manner is shown as function of temperature in Figs. 4(b) and 4(d). The value of $M \mathrm{~s}$ at $5 \mathrm{~K}$ of the LM steel is $208.5 \mathrm{Am}^{2} / \mathrm{kg}\left(1.999 \mu_{\mathrm{B}} /\right.$ atom $)$ and that of the $\mathrm{HM}$ steel is $204.3 \mathrm{Am}^{2} / \mathrm{kg}\left(1.985 \mu_{\mathrm{B}} /\right.$ atom $)$. It decreases monotonically as temperature increases.

Figure 5(a) shows temperature dependence of specific heat $C p$ of the two steels below $300 \mathrm{~K}$, and (b) is the magnification below $16 \mathrm{~K}$. We notice that $C p$ of the $\mathrm{HM}$ steel is slightly higher than that of the LM steel. Below $16 \mathrm{~K}, C p$ of both steels can be fitted as $C p=\gamma T+\beta T^{3}$ with electronic specific heat coefficient of $\gamma=5.2 \mathrm{~mJ} / \mathrm{mol} \cdot \mathrm{K}^{2}$ for the LM steel and $\gamma=5.4 \mathrm{~mJ} / \mathrm{mol} \cdot \mathrm{K}^{2}$ for the $\mathrm{HM}$ steel and lattice specific heat coefficient of $\beta=0.0194 \mathrm{~mJ} / \mathrm{mol} \cdot \mathrm{K}^{4}$ for the LM steel and $\beta=0.0188 \mathrm{~mJ} / \mathrm{mol} \cdot \mathrm{K}^{4}$ for the HM steel. Then from $\beta$, the Debye temperature is obtained to be $464 \mathrm{~K}$ for the LM steel and $469 \mathrm{~K}$ for the HM steels. The values are almost consistent with that of pure $\mathrm{Fe}(480 \mathrm{~K})^{21)}$ evaluated by the same method.

Elastic constants obtained from sound velocities are shown in Table 1. As shown in table, the values of $C_{11}$, $C_{12}$ of the LM steel are slightly larger than those of the HM steel. While the value of $C_{44}$ of the LM steel are slighter 

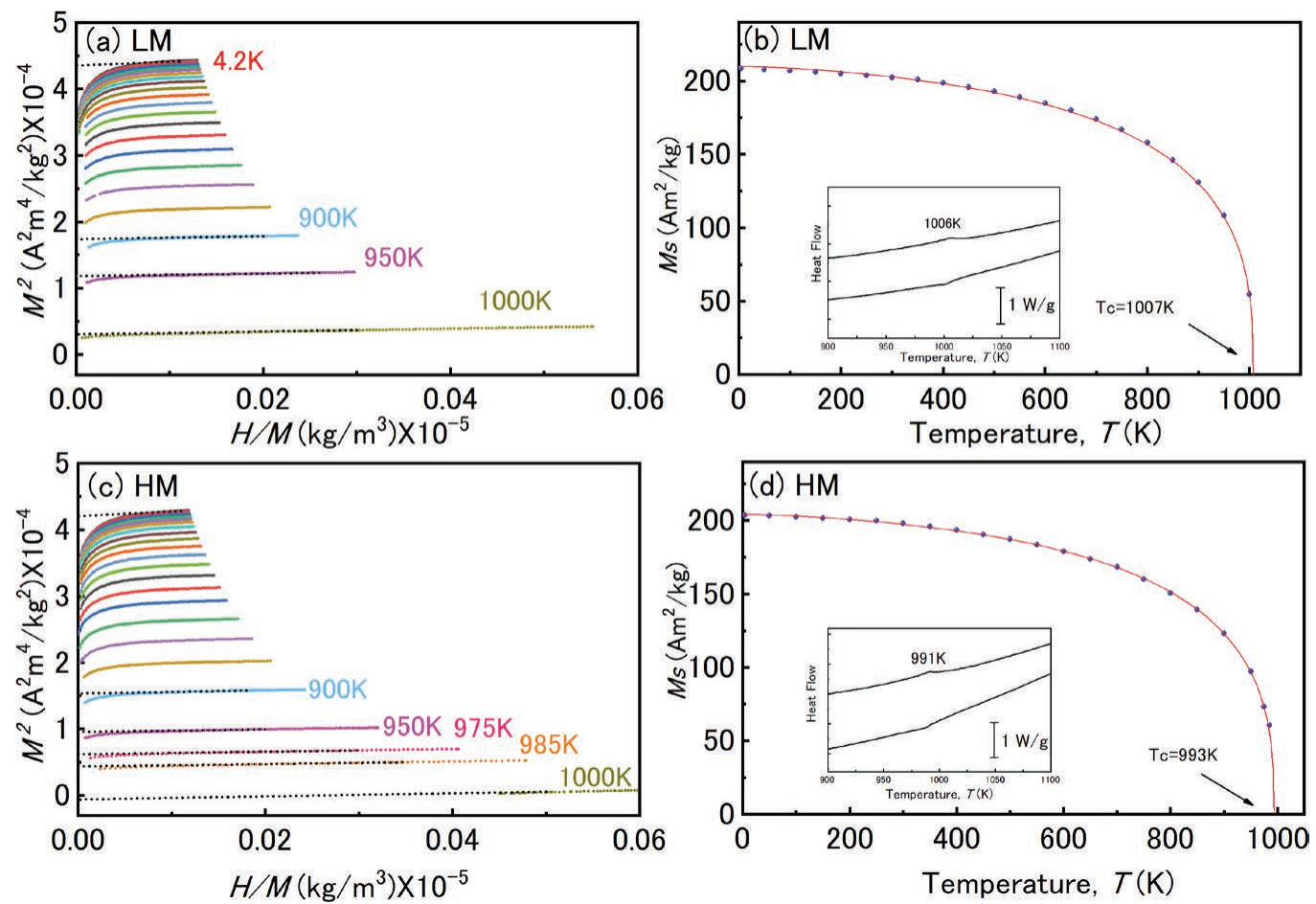

Fig. 4. $M^{2}$ vs. $H / M$ plots (a), (c) and temperature dependence of $M \mathrm{~s}$ (b), (d). (a) and (b) correspond to the LM steel, and (c) and (d) correspond to the HM steel. Insert shows DSC measurement result. (Online version in color.)
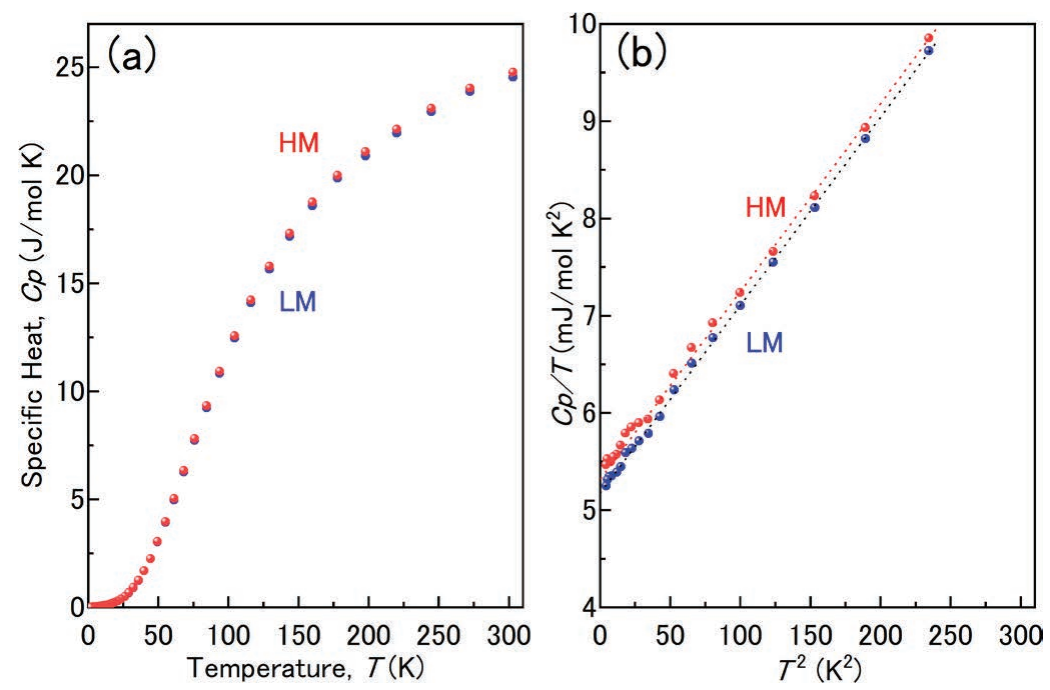

Fig. 5. Temperature dependence of specific heat $C p$ (a) and the $C p / T$ vs. $T^{2}$ relation in low temperature region (b) of the LM and the HM steels. (Online version in color.)

Table 1. Elastic constants at room temperature of the LM steel and the HM steel.

\begin{tabular}{|c|c|c|c|c|c|}
\hline & $C_{11}(\mathrm{GPa})$ & $C_{12}(\mathrm{GPa})$ & $C_{44}(\mathrm{GPa})$ & $C^{\prime}(\mathrm{GPa})$ & $C_{44} / C^{\prime}$ \\
\hline LM steel & 202 & 126 & 112 & 38 & 2.95 \\
\hline HM steel & 200 & 120 & 117 & 40 & 2.93 \\
\hline Pure iron ${ }^{22)}$ & 228 & 132 & 117 & 48 & 2.44 \\
\hline
\end{tabular}

smaller than that of the HM steel. The Debye temperature at room temperature was also evaluated from average sound velocity as $394 \mathrm{~K}$ for the LM steel and $402 \mathrm{~K}$ for the HM steels. They are slightly lower than that evaluated from specific heat.

\section{Discussion}

First, we determined the Curie temperature Tc from temperature dependence of $M$ s by using Eq. (3) proposed by M. D. Kuz'min, ${ }^{23)}$ which is expressed as:

$$
M s(T)=M s(0)\left\{1-s\left(\frac{T}{T c}\right)^{\frac{3}{2}}-(1-s)\left(\frac{T}{T c}\right) p\right\}^{\frac{1}{3}},
$$

where, $p$ and $s$ are fitting parameters, $p>3 / 2, s>0$. In case of bcc Fe, $p=4$. The best-fit parameters of $s$ are 0.51 for the LM steel and 0.57 for the HM steel and fitting curves obtained are shown in Figs. 5(b) and 5(d). The value Tc is also fitted to be $1007 \mathrm{~K}$ for the LM steel and $993 \mathrm{~K}$ for the 
HM steel. The Tc thus determined is in good agreement with that obtained by DSC measurement as shown by the inset in Figs. 5(b) and 5(d).

Next, we check whether the difference of $M$ s between the $\mathrm{LM}$ and HM steels at absolute zero $\left(\Delta M \mathrm{~s}=0.014 \mu_{\mathrm{B}} /\right.$ atom $)$ agrees with that expected from the Slater-Pauling's curve. The value of electron concentration (e/a) is 7.667 for the LM steel and 7.657 for the HM steel. Then $\Delta \mathrm{e} / \mathrm{a}=0.010$ electron/ atom and the slope of the Slater-Pauling's curve becomes $1.40 \mu_{\mathrm{B}}$ /electron. The slope is consistent with that of the established Slater-Pauling's curve (1.41 $\mu_{\mathrm{B}}$ /electron). ${ }^{24)}$

We next discuss the relation between $K_{1}$ and $M$ s. In general, $K_{1}$ of metals decrease very rapidly than that of $M \mathrm{~s}$ with increasing temperature, which is well known as following Eq. (4), ${ }^{25)}$

$$
\frac{K 1(T)}{K 1(0)}=\left(\frac{M s(T)}{M s(0)}\right)^{\frac{n(n+1)}{2}}
$$

where, $T$ and 0 in parentheses refer to measured temperature and absolute zero, respectively. In order to confirm whether Eq. (4) is satisfied for the LM and HM steels, we made $\ln \left\{K_{1}(\mathrm{~T}) / K_{1}(0)\right\}$ vs. $\ln \{M \mathrm{~s}(\mathrm{~T}) / M \mathrm{~s}(0)\}$ plot, which is shown in Fig. 6. The slope $\alpha$ is 10 at the region of $\ln \{M \mathrm{~s}(\mathrm{~T}) / M \mathrm{~s}(0)\}>-0.10$, which corresponds to the temperature of below $600 \mathrm{~K}$ for pure iron, $550 \mathrm{~K}$ for the LM steel and $500 \mathrm{~K}$ for the HM steel. This is consistent with $\mathrm{n}=$ 4 for the slope $\alpha$ is given by $\mathrm{n}(\mathrm{n}+1) / 2$. That is, the temperature dependence of $K_{1}$ is satisfied the tenth power law $(\mathrm{n}=4)$ of $M \mathrm{~s}$ in relatively low temperature region, being consistent with previous report on bcc Fe. ${ }^{25)}$ Therefore, we can conclude that the $K_{1}$ obtained in the present study is reliable. However, it is slightly out of the range of $\alpha=10$ at the region of $\ln \{M \mathrm{~s}(\mathrm{~T}) / M \mathrm{~s}(0)\}<-0.10$, which is probably due to relatively large noise in magnetization curves.

Finally, we discuss the abnormal behavior in electrical resistivity of the HM steel in a low temperature region. In metals and alloys, the resistivity is proportional to the fifth power of the temperature in a low temperature region. As

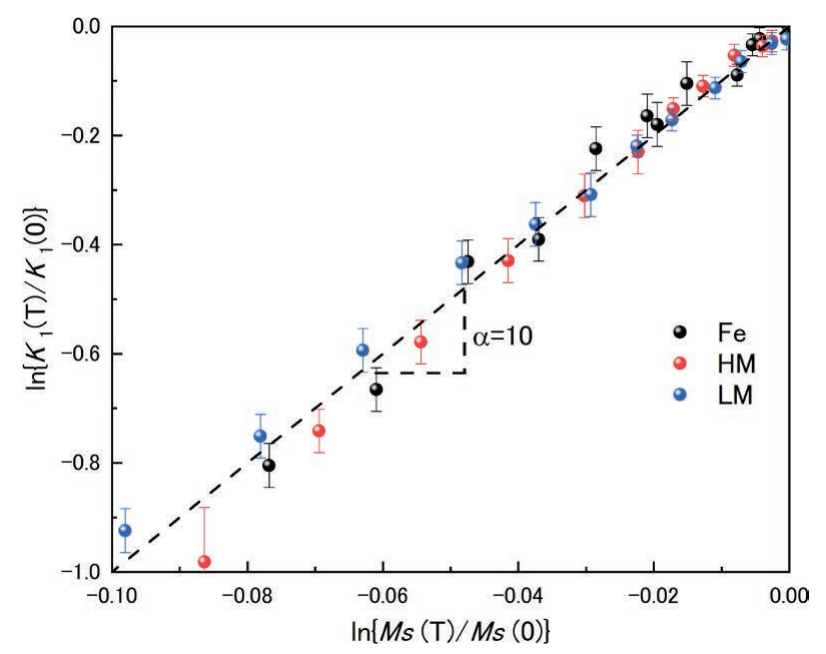

Fig. 6. The relationship between $\ln \left\{K_{1}(\mathrm{~T}) / K_{1}(0)\right\}$ and $\ln \{M \mathrm{~s}(\mathrm{~T}) /$ $M \mathrm{~s}(0)\}$ for pure iron, the LM and the HM steels. (Online version in color.) shown in Fig. 1(b), the resistivity of the LM steel is proportional to $T^{5}$, while that of the HM steel (Fig. 1(c)) is not proportional to $T^{5}$. The anomaly in resistivity is speculated to be due to Mn doping, but no noticeable changes in electronic, lattice and magnetic structures were observed. For example, from the specific heat measurement, electronic specific heat coefficient and Debye temperature of both steels obtained were almost the same at low temperature region, meaning that the electronic and lattice structure are almost the same for both steels. In addition, no anomalies can be seen in spontaneous magnetization (Fig. 4). Additional study is needed to understand the role of $\mathrm{Mn}$ on abnormal behavior in resistivity.

\section{Conclusions}

We have examined magnetic, electrical, thermal and elastic properties of electrical steel with different $\mathrm{Mn}$ content: 0.3 mass\% Mn (LM steel) and 1.5 mass\% Mn (HM steel). The electrical resistivity of the HM steel is by $13 \%$ higher than that of the LM steel at $5 \mathrm{~K}$, and the difference decreases as temperature increases. The magnetocrystalline anisotropy constant $K_{1}$, spontaneous magnetization $M$ s and Curie temperature $T \mathrm{c}$ in the HM steel is lower than those of the LM steel. The Debye temperature and elastic constants are almost the same for the LM and the HM steels. Therefore, it is possible to improve the iron loss without deteriorating the cold workability by adding Mn.

\section{Acknowledgement}

We appreciate technical support by Dr. M. Yoshizawa (Iwate University) for the measurements of elastic constants.

\section{REFERENCES}

1) K. Matsumura and B. Fukuda: IEEE Trans. Magn., 20 (1984), 1533.

2) S. da Costa Paolinelli, M. A. da Cunha and A. B. Cota: J. Magn. Magn. Mater., 320 (2008), e641.

3) P. Beckley: Electrical Steels for Rotating Machines, IET, The Institution of Engineering and Technology, Stevenage, (2002), 23.

4) Y. B. Cai and S. Chang: ISIJ Int., 47 (2007), 1680.

5) S. Lee and B. C. De Cooman: ISIJ Int., 51 (2011), 1545

6) V. V. Basabe: ISIJ Int., 57 (2017), 148.

7) M. F. Littmann: IEEE Trans. Magn., 7 (1971), 48

8) P. Brissonneau: J. Magn. Magn. Mater., 41 (1984), 38.

9) K. E. Thelning: Steel and Its Heat Treatment, Butterworth-Heinemann, Smedjebackens Valsverks AB, Oxford, (1984), 15.

10) M. F. de Campos, J. C. Teixeira and F. J. G. Landgraf: J. Magn. Magn. Mater., 301 (2006), 94.

11) M. Shiozaki and Y. Kurosaki: J. Mater. Eng., 11 (1989), 37.

12) H. Yashiki and T. Kaneko: ISIJ Int., 30 (1990), 325.

13) K. Jenkins and M. Lindenmo: J. Magn. Magn. Mater., 320 (2008), 2423.

14) T. Nakayama, N. Honjou, T. Minaga and H. Yashiki: J. Magn. Magn. Mater., 234 (2001), 55.

15) P. Arató, I. Bóc and T. Gróf: J. Magn. Magn. Mater., 41 (1984), 53.

16) T. Senuma: ISIJ Int., 42 (2002), 1.

17) C. Hou: ISIJ Int., 36 (1996), 563.

18) D. C. Ludwigson and F. C. Schwerer: Metall. Trans., 2 (1971), 3500.

19) H. Gengnagel and U. Hofmann: Phys. Status Solidi, 29 (1968), 91.

20) A. Arrott: Phys. Rev., 108 (1957), 1394.

21) F. Xiao, T. Fukuda, T. Yamaguchi, K. Sato and T. Kakeshita: Scr. Mater., 139 (2017), 92.

22) A. E. Lord, Jr. and D. N. Beshers: J. Appl. Phys., 36 (1965), 1620.

23) M. D. Kuz'min: Phys. Rev. Lett., 94 (2005), 107204.

24) R. M. Bozorth: Phys. Rev., 79 (1950), 887.

25) C. Zener: Phys. Rev., 96 (1954), 1335. 